\title{
Genetic parameters of total milk yield and factors describing the shape of lactation curve in dairy buffaloes
}

\author{
Rúsbel R Aspilcueta-Borquis ${ }^{1}$, Fernando Baldi ${ }^{1}$, Francisco R Araujo Neto ${ }^{1}$, Lucia G Albuquerque ${ }^{1,2}$, \\ Milthon Muñoz-Berrocal ${ }^{3}$ and Humberto Tonhati ${ }^{1,2 *}$ \\ ${ }^{1}$ Department of Animal Science, São Paulo State University (FCAV/UNESP), Jaboticabal, SP, Brazil, 14884900 \\ ${ }^{2}$ Conselho Nacional de Desenvolvimento Científico e Tecnologico (CNPq) and Instituto Nacional de Ciência e Tecnologia - Ciência Animal \\ (INCT-CA), Viçosa, MG, Brazil, 36570000 \\ ${ }^{3}$ Universidad Nacional Agraria de la Selva, Aptdo. 156, UNAS-Tingo Maria-Peru
}

Received 21 July 2011; accepted for publication 7 September 2011; first published online 7 November 2011

\begin{abstract}
The objective of this study was to apply factor analysis to describe lactation curves in dairy buffaloes in order to estimate the phenotypic and genetic association between common latent factors and cumulative milk yield. A total of 31257 monthly test-day milk yield records from buffaloes belonging to herds located in the state of São Paulo were used to estimate two common latent factors, which were then analysed in a multi-trait animal model for estimating genetic parameters. Estimates of (co)variance components for the two common latent factors and cumulated 270-d milk yield were obtained by Bayesian inference using a multiple trait animal model. Contemporary group, number of milkings per day (two levels) and age of buffalo cow at calving (linear and quadratic) as covariate were included in the model as fixed effects. The additive genetic, permanent environmental and residual effects were included as random effects. The first common latent factor (F1) was associated with persistency of lactation and the second common latent factor (F2) with the level of production in early lactation. Heritability estimates for F1 and F2 were $0 \cdot 12$ and $0 \cdot 07$, respectively. Genetic correlation estimates between F1 and F2 with cumulative milk yield were positive and moderate $(0.63$ and 0.52$)$. Multivariate statistics employing factor analysis allowed the extraction of two variables (latent factors) that described the shape of the lactation curve. It is expected that the response to selection to increase lactation persistency is higher than the response obtained from selecting animals to increase lactation peak. Selection for higher total milk yield would result in a favourable correlated response to increase the level of production in early lactation and the lactation persistency.
\end{abstract}

Keywords: Multivariate analysis, Gibbs sampler, buffaloes, genetic parameters, milk yield.

The use of test-day (TD) milk yield records to model the lactation curve is important in dairy cattle systems since it helps dairy producers to make decisions on feeding and reproductive management, culling of animals and selection programmes. Knowledge of two attributes of the lactation curve is important in taking these decisions, i.e. the lactation peak and lactation persistency. Compared with cows' milk, buffalo milk has a higher percentage of all components, such as protein and fat, and lower cholesterol content (Rosati \& Van Vleck, 2002; Zicarelli, 2004). Despite these advantages, buffalo milk yield is still much lower than that of cows and

*For correspondence; e-mail: tonhati@fcav.unesp.br short lactation length is common in buffaloes (Tonhati et al. 2008).

Several definitions and approaches to describe lactation curves are reported in the literature. One widely used method is the modelling of lactation curves using mathematical functions, such as the Wilmink and Ali \& Schaeffer functions (Wilmink, 1987a; Ali \& Schaeffer, 1987). In this sense, Macciotta et al. (2004) applied the Wilmink function to model TD records of milk yield of Italian river buffaloes. These parametric functions allow the estimation of the rate of milk yield increase until lactation peak, as well as the rate of decline after the lactation peak, with the measurement of persistency being based on milk production.

Another method proposed to study lactation curves is based on the combination of TD milk yield records obtained at different stages of lactation and the analysis of the 
relationships between cumulative yields or measures of TD milk yield variation (Swalve, 1995). However, this method does not characterize persistency in a unique manner because it is not invariant in terms of the time period chosen (Rekaya et al. 2001). The main disadvantage of this method is that it attributes arbitrary relative values to weighted TD milk yield records obtained at different stages of lactation (Haile-Mariam et al. 2003). Another problem encountered is that a large number of parameters have to be estimated, and problems of modelling the records at the extremes of the lactation curve are common (Jamrozik et al. 1997).

The application of multivariate methods, such as principal component analysis or factor analysis, have been proposed by Wilmink (1987b), Pool et al. (2000), Macciotta et al. (2004) and Macciotta et al. (2006) to obtain latent variables that describe the shape of the lactation. Factor analysis can be applied to explain all covariances or correlations using few unobserved variables, called common latent factors. In this model, each variable is represented by a linear function of unobserved factorial variables (common factors) and by a single specific latent variable, which contribute only to the variances of variables included in the model. Although there are some studies on using factor analysis for breeding purposes in dairy cattle (Macciotta et al. 2006; Yilmaz et al. 2011), published reports using this approach to describe the shape of the lactation curve in other species such as buffaloes are scarce. The objective of the present study was to apply multivariate factor analysis to extract new variables that describe the shape of lactation curves in dairy buffaloes, based on the phenotypic correlation matrix of monthly TD milk yield records. In addition, the genetic association between these new variables and cumulated 270-d milk yield was evaluated using Bayesian inference.

\section{Materials and Methods}

\section{Data and database consistency}

A total of 31257 monthly TD milk yield records obtained from 3798 lactations of Murrah buffaloes, daughters of 140 bulls, belonging to 12 herds located in the state of São Paulo, whose calving records comprised the period from 1998 to 2007, were analysed. It was considered that the first TD milk yield record was measured from $5^{\text {th }}$ to $45^{\text {th }}$ day after calving. Cow age varied from 2 to 7 years. There were 1052, 906, 751, 622 and 467 lactations of first, second, third, fourth and fifth parities, respectively. The TD milk yield records were divided into monthly classes of days in lactation (classes 1 to 10 ).

The first seven monthly TD records were considered for the factor analyses, since the number of TD records decreased after the $7^{\text {th }}$ lactation month (Table 2). Only animals that had the first seven TD records were included in the analysis, since this is a basic requirements of multivariate analysis. The general structure of the data is shown in Table 1. To obtain the cumulated $270-\mathrm{d}$ milk yield, the
Table 1. Structure and descriptive statistics of the milk yield records Number of observations 31257

Sires 140

Cows 1986

Mean, $\mathrm{kg}$

$\mathrm{SD}, \mathrm{kg}$ $1714 \cdot 3$

Minimum, $\mathrm{kg}$

$524 \cdot 3$

Maximum, $\mathrm{kg}$

$520 \cdot 2$

Contemporary group

$4716 \cdot 2$

708

Table 2. Descriptive statistics and number $(\mathrm{N})$ of the test-day milk yield records (TD)

$\begin{array}{lllll} & \mathrm{N} & \text { Mean, kg } & \text { SD, kg } & \begin{array}{l}\text { Coefficients } \\ \text { variance, \% }\end{array} \\ \text { TD1 } & 3798 & 7 \cdot 17 & 3 \cdot 20 & 44 \cdot 63 \\ \text { TD2 } & 3798 & 8 \cdot 63 & 3 \cdot 53 & 40 \cdot 90 \\ \text { TD3 } & 3798 & 8 \cdot 55 & 3 \cdot 56 & 41 \cdot 65 \\ \text { TD4 } & 3798 & 8 \cdot 09 & 3 \cdot 46 & 42 \cdot 79 \\ \text { TD5 } & 3798 & 7 \cdot 52 & 3 \cdot 23 & 42 \cdot 93 \\ \text { TD6 } & 3798 & 6 \cdot 91 & 3 \cdot 00 & 43 \cdot 46 \\ \text { TD7 } & 3798 & 6 \cdot 19 & 2 \cdot 69 & 43 \cdot 47\end{array}$

lactations were adjusted using the method proposed by Tonhati et al. (2004), and lactations with a length above 270-d were truncated at this point. Lactations shorter than $90 \mathrm{~d}$ were deleted.

\section{Factor analysis and latent variables}

Considering each monthly TD milk yield record to be a distinct trait, the model of common factors can be expressed in matrix form as follows:

$y=\Lambda f+\varepsilon$

where $y, f$ and $\varepsilon$ are $p$-dimensional vectors corresponding to TD milk yield records, a vector $(\mathrm{m} \times 1)$ of latent common factors, and a vector of errors, respectively, and $\Lambda$ is a matrix $(\mathrm{p} \times \mathrm{m})$ of coefficients known as factor loadings. Using orthogonal factors, the following assumptions were established:

$E(y)=E(\varepsilon)=E(f)=0 ; \operatorname{Cov}(f, \varepsilon)=0 ; \Sigma=\Lambda \Lambda^{\prime}+\Psi$

Where, $\Sigma=($ co)variance matrix between TD milk yield records and $\Psi=$ identity matrix of residual (co)variance. Statistica software (2007) was used for the extraction of latent factors by the maximum likelihood method and rotation was performed by the varimax technique. The factors are represented in a Cartesian coordinate system with two axes. In the present study, two factors were chosen as proposed in the studies of Macciotta et al. (2004, 2006).

\section{Quantitative genetic analysis}

The (co)variance components for two common latent factors and cumulated $270-d$ milk yield were estimated by Bayesian 
multi-trait analysis using the GIBBS2F90 program (Misztal, 2007). The contemporary group for studied traits was defined as animals that calved in the same herd, year and season (season $=1$ from April to September and season $=2$ from October to March). The CG with less than 5 lactations (animals) were deleted from the analyses. The animal model included the following fixed effects: contemporary group, number of milkings per day (two levels), and age of buffalo cow at calving (linear and quadratic effect), ranging from 2 to 6 years, as covariate. The additive genetic, permanent environmental and residual effects were included as random effects in the model. The matrix form of the complete model can be written as follows:

$y=X \beta+Z a+W p+e$

where $y, \beta, a, p$, and e are vectors of observations, fixed, direct additive genetic, permanent environmental and residual effects, respectively, and $X, Z$ and $W$ are incidence matrices of fixed effects and direct additive genetic and permanent environmental random effects, respectively. A uniform distribution was defined a priori for the fixed effects $(\beta)$, which reflects vague prior knowledge about this vector. Gaussian distributions were used for random effects and an inverse Wishart distribution for the (co)variance components:

$$
\begin{array}{ll}
b \propto \text { constant } & a \mid G \sim \operatorname{MVN}[0,(G \otimes A)] \\
p \mid P \sim \operatorname{MVN}\left[0,\left(P \otimes I_{n}\right)\right] & G \mid S_{g}, v_{g} \sim I W\left[S_{g} v_{g}, v_{g}\right] \\
P \mid S_{p}, v_{p} \sim I W\left[S_{p} v_{p}, v_{p}\right] & R \mid S_{r}, v_{r} \sim I W\left[S_{r} v_{r}, v_{r}\right]
\end{array}
$$

where $A, G, P, R$, and $I_{n}$ correspond to (co)variance matrices of direct additive genetic, permanent environmental and residual effects, relationship matrix, and identity matrix, respectively; $\otimes$ is the Kronecker direct product operator, and $S_{g}$ and $v_{g}, S_{p}$ and $v_{p}$, and $S_{r}$ and $v_{r}$ are a priori values and the degrees of freedom for additive genetic, permanent environmental and residual (co)variances, respectively.

After a burn-in period of 100000 cycles, 2000000 samples were generated using a sampling interval of 50 cycles. Next, the Gibanal program (Van Kaam, 1997) was used for the analysis of convergence and to obtain estimates derived from independent samples. For the description of posterior distributions, the mean was used as a point estimate and the highest posterior density interval as a measure of dispersion.

\section{Results and Discussion}

The scoring coefficients and factor loading of the two factors after rotation are shown in Table 3. The factor loadings are coefficients of correlation between each factor and each TD milk yield record. Factor loadings higher than $0 \cdot 65$, in absolute values, pointed out the strongest indicators associated with each factor. The results show that factor analysis was able to extract two latent factors from the phenotypic correlation matrix of TD milk yield records, which explain $91 \%$ of the original variance of the data (Table 3). Similar

\begin{tabular}{|c|c|c|c|c|}
\hline \multirow[b]{2}{*}{ Variable } & \multicolumn{2}{|c|}{ Scoring coefficients } & \multicolumn{2}{|c|}{ Factor loading } \\
\hline & $\mathrm{F} 1+$ & $\mathrm{F} 2$ & $\mathrm{~F} 1$ & F2 \\
\hline TD1 & -0.55 & $0 \cdot 85$ & $0 \cdot 32$ & 0.90 \\
\hline TD2 & $-0 \cdot 19$ & $0 \cdot 46$ & $0 \cdot 55$ & $0 \cdot 78$ \\
\hline TD3 & -0.001 & $0 \cdot 25$ & $0 \cdot 65$ & 0.67 \\
\hline TD4 & $0 \cdot 16$ & $0 \cdot 06$ & $0 \cdot 73$ & $0 \cdot 60$ \\
\hline TD5 & $0 \cdot 32$ & $-0 \cdot 12$ & $0 \cdot 80$ & $0 \cdot 51$ \\
\hline TD6 & $0 \cdot 46$ & $-0 \cdot 28$ & $0 \cdot 85$ & $0 \cdot 43$ \\
\hline TD7 & $0 \cdot 58$ & $-0 \cdot 44$ & $0 \cdot 89$ & $0 \cdot 33$ \\
\hline $\begin{array}{l}\text { Variance } \\
\text { explained, \% }\end{array}$ & & & $0 \cdot 51$ & $0 \cdot 40$ \\
\hline
\end{tabular}

Table 3. Scoring coefficients and factor loading between test-day (TD) milk yield records and latent variables and variance explained by the factors

FF1: latent factor related to lactation persistency; F2: latent factor related to lactation peak

results were reported by Macciota et al. (2006) and Yilmaz et al. (2011), who reported that two factors explained $80 \cdot 0 \%$ and $82 \cdot 8 \%$ of variance data, using the same approach applied in the present study for 7 TD and 10 TD milk yield records, in Simmental and Brown Swiss cattle, respectively.

The first latent factor (F1) was positively and strongly correlated with the last three TD, indicating a relationship with the rate of milk yield decline after lactation peak. In milking buffaloes, the lactation peak normally occurs 2 months after calving (Tonhati et al. 2008; Aspilcueta et al. 2010). Thus, it can be stated that the second latent factor (F2) was associated with the rate of milk yield increase to the peak of lactation, since this factor was strongly associated with the first two monthly TD (TD1 and TD2). The association was stronger with TD1 (0.90), and slightly weaker with TD2 (0.78). Given that the within-variance for TD1 and TD2 is approximately the same (Table 2), an increase in F2 is expected to lead to a similar increase in the 2 monthly testday associations, just a little stronger for TD1. This means that an increase in F2 involves a greater increase in pre-peak milk yield (level of production in early lactation) and a smaller increase in peak milk yield. Furthermore, the scoring coefficients confirm these results (Table 3).

Similar results have been reported in dairy cattle by Macciotta et al. (2006) and Yilmaz et al. (2011), who identified two latent factors at the phenotypic level, the first associated with lactation peak and the second one related with persistency of lactation. Although Macciotta et al. (2006) reported heritability estimate for the factor associated with lactation peak, the factors estimated in the present study could not express the same thing, owing to different correlations between common latent factors and the first three TDs. There are several differences between the lactation curve in buffaloes and the lactation curve dairy cattle. In buffaloes, the lactation peak is less noticeable or accentuated and short-length lactations are common. Probably these aspects affect the results obtained in the present study with 
Table 4. Estimates of variance components and genetic parameters for cumulative milk yield and common factors (F1 and F2)

\begin{tabular}{|c|c|c|c|c|c|c|c|}
\hline & & & & & & & \\
\hline & Parametert & Mean & Mode & Median & SD & LL & UL \\
\hline Milk yield & $\sigma_{a}^{2}$ & 39580 & 35419 & 37120 & 14304 & 11630 & 96570 \\
\hline & $\sigma_{a p}^{2}$ & 52453 & 49295 & 51910 & 11111 & 25520 & 89790 \\
\hline & $\sigma_{r}^{2}$ & 112990 & 112896 & 112900 & 4468 & 97650 & 133800 \\
\hline & $\sigma_{p}^{2}$ & 205206 & 197622 & 201925 & 7654 & 167190 & 254610 \\
\hline & $\mathrm{h}^{2}$ & $0 \cdot 20$ & 0.21 & 0.20 & 0.06 & 0.06 & 0.38 \\
\hline & $c^{2}$ & $0 \cdot 26$ & $0 \cdot 25$ & $0 \cdot 26$ & 0.03 & $0 \cdot 21$ & $0 \cdot 35$ \\
\hline F1 & $\sigma_{a}^{2}$ & $0 \cdot 11$ & $0 \cdot 11$ & $0 \cdot 11$ & 0.03 & 0.03 & $0 \cdot 21$ \\
\hline & $\sigma_{a p}^{2}$ & $0 \cdot 10$ & $0 \cdot 10$ & $0 \cdot 10$ & 0.02 & 0.03 & $0 \cdot 20$ \\
\hline & $\sigma_{r}^{2}$ & 0.69 & 0.69 & 0.69 & 0.03 & 0.60 & $0 \cdot 80$ \\
\hline & $\sigma_{p}^{2}$ & $0 \cdot 90$ & 0.90 & 0.90 & $0 \cdot 04$ & $0 \cdot 72$ & $1 \cdot 11$ \\
\hline & $h^{2}$ & $0 \cdot 12$ & $0 \cdot 11$ & $0 \cdot 12$ & $0 \cdot 03$ & $0 \cdot 04$ & $0 \cdot 19$ \\
\hline & $c^{2}$ & $0 \cdot 11$ & $0 \cdot 12$ & $0 \cdot 11$ & $0 \cdot 04$ & $0 \cdot 04$ & $0 \cdot 18$ \\
\hline F2 & $\sigma_{a}^{2}$ & 0.06 & $0 \cdot 05$ & 0.06 & $0 \cdot 02$ & 0.03 & $0 \cdot 18$ \\
\hline & $\sigma_{a p}^{2}$ & $0 \cdot 07$ & $0 \cdot 07$ & $0 \cdot 07$ & $0 \cdot 03$ & $0 \cdot 02$ & $0 \cdot 14$ \\
\hline & $\sigma_{r}^{2}$ & $0 \cdot 70$ & $0 \cdot 71$ & $0 \cdot 70$ & $0 \cdot 03$ & $0 \cdot 61$ & $0 \cdot 80$ \\
\hline & $\sigma_{p}^{2}$ & $0 \cdot 83$ & $0 \cdot 83$ & $0 \cdot 82$ & $0 \cdot 02$ & $0 \cdot 69$ & 0.94 \\
\hline & $\mathrm{h}^{2}$ & $0 \cdot 07$ & 0.06 & 0.07 & 0.03 & 0.04 & $0 \cdot 19$ \\
\hline & $c^{2}$ & $0 \cdot 08$ & 0.08 & 0.08 & $0 \cdot 02$ & 0.03 & $0 \cdot 15$ \\
\hline
\end{tabular}

+Parameters: $\sigma_{a}^{2}=$ additive genetic variance; $\sigma_{a p}^{2}=$ variance attributed to permanent environmental effects; $\sigma_{r}^{2}=$ residual variance; $\sigma_{p}^{2}=$ phenotypic variance; $\mathrm{h}^{2}=$ heritability; $\mathrm{c}^{2}=$ proportion of total variance due to permanent environmental effects; $\mathrm{HPD}=$ highest posterior density interval; $\mathrm{LL}=$ lower limit; $\mathrm{UL}=$ upper limit

factor analyses as well as the comparisons between factor analyses results between dairy cattle and buffaloes.

The genetic parameter estimates for cumulated 270-d milk yield and the latent factors (F1 and F2) are shown in Table 4. The heritability estimate for cumulated $270-\mathrm{d}$ milk yield was moderate, indicating that this trait should respond to selection. Studies on Murrah buffaloes conducted in Brazil have reported heritability estimates for cumulated 305-d milk yield close to that found in the present investigation $(0 \cdot 22)$ (Tonhati et al. 2008). In contrast, lower estimates have been reported by Rosati \& Van Vleck (2002) (0.14) for an Italian buffalo breed, and by Thevamanohar et al. (2000) $(0 \cdot 17)$ for Pakistani Nili-Ravi buffaloes.

The heritability estimate for F1 was low, suggesting that the lactation curve after the lactation peak can be modified, in the long term, by selection. Studies estimating heritabilities for lactation persistency in buffaloes are scarce. In this respect, Chaves et al. (2010) using random regression models and various measures of persistency obtained between 30 and $280 \mathrm{~d}$ of lactation, obtained heritability estimates ranging from 0.16 and 0.37 in dairy buffaloes. Applying a multivariate approach, similar to that proposed in the present study, Macciotta et al. (2006), using factor and principal component analysis related to persistency, reported heritability estimates for persistency of 0.13 (factor analysis) and 0.07 (principal component analysis) in Italian Simmental cows. Also, Yilmaz et al. (2011) obtained a similar heritability estimate for persistency $(0 \cdot 15)$, from factor analysis defining latent variables for lactation curves, in Brown Swiss cattle. In dairy cattle, Van der Linde et al. (2000)
Table 5. Estimates of genetic, permanent, residual and phenotypic correlations between cumulative milk yield (MY) and common factors (F1 and F2)

\begin{tabular}{|c|c|c|c|c|}
\hline & & & & \\
\hline & Mean & SD & LL & UL \\
\hline & & netic & & \\
\hline MY/F1 & 0.63 & 0.04 & 0.57 & $0 \cdot 72$ \\
\hline MY /F2 & 0.52 & 0.04 & $0 \cdot 48$ & 0.63 \\
\hline $\mathrm{F} 1 / \mathrm{F} 2$ & $0 \cdot 12$ & 0.05 & 0.06 & $0 \cdot 18$ \\
\hline & Per & enviror & & \\
\hline MY /F1 & $0 \cdot 66$ & 0.05 & $0 \cdot 60$ & $0 \cdot 74$ \\
\hline MY /F2 & $0 \cdot 44$ & 0.04 & $0 \cdot 41$ & $0 \cdot 54$ \\
\hline $\mathrm{F} 1 / \mathrm{F} 2$ & $0 \cdot 13$ & $0 \cdot 05$ & 0.07 & $0 \cdot 22$ \\
\hline & & idual & & \\
\hline $\mathrm{MY} / \mathrm{F} 1$ & $0 \cdot 54$ & 0.02 & $0 \cdot 44$ & 0.60 \\
\hline MY /F2 & $0 \cdot 40$ & 0.02 & $0 \cdot 30$ & $0 \cdot 46$ \\
\hline $\mathrm{F} 1 / \mathrm{F} 2$ & $0 \cdot 14$ & 0.02 & $0 \cdot 10$ & $0 \cdot 22$ \\
\hline & & otypic & & \\
\hline MY /F1 & $0 \cdot 66$ & 0.04 & $0 \cdot 55$ & $0 \cdot 70$ \\
\hline PL/F2 & $0 \cdot 32$ & 0.03 & $0 \cdot 22$ & $0 \cdot 41$ \\
\hline F1/F2 & $0 \cdot 44$ & 0.03 & $0 \cdot 36$ & $0 \cdot 50$ \\
\hline
\end{tabular}

$+\mathrm{HPD}=$ highest posterior density interval; $\mathrm{LL}=$ lower limit; $U L=$ upper limit

and Muir et al. (2004) defined lactation persistency as the Wilmink b parameter for milk yield, and obtained heritability estimates for persistency, ranging from $0 \cdot 15$ to $0 \cdot 18$. Applying random regression models using various measures of persistency, Cobuci et al. (2004) and Dorneles et al. 
(2009) obtained heritability estimates for persistency ranging from $0 \cdot 05$ to $0 \cdot 27$, in dairy cattle.

The heritability estimated for latent factor F2 was low, suggesting that selection response to modify the rate of milk yield increase until lactation peak, would be slow. No heritability estimates for this trait have been reported in the literature for dairy buffaloes. In dairy cattle, Macciotta et al. (2006) and Yilmaz et al. (2011) using factor analyses to describe the lactation curve, reported low heritability estimates, $0 \cdot 13$ and $0 \cdot 13$, respectively, for the common latent factor related to level of production in early lactation.

The estimates of genetic and phenotypic correlations between the two factors (F1 and F2) and cumulated 270-d milk yield are shown in Table 5 . The genetic correlation between milk yield and F1 was moderate and similar to that reported by Macciotta et al. (2006) for dairy cattle $(0 \cdot 61)$. However, Yilmaz et al. (2011) with a small data set, reported higher genetic correlation estimate $(1 \cdot 0)$ between lactation persistency (second latent factor) with 305-d milk yield in Brown Swiss cattle. Applying other approaches to assess lactation persistency, a wide variation in the genetic correlation estimates between milk yield and persistency has been reported in the literature $(0 \cdot 0$ to $0 \cdot 60)$ (Rekaya et al. 2000; Van der Linde et al. 2000; Muir et al. 2004). The results obtained in the present study suggest that selection for higher cumulated 270-d milk yield should result in an increase of lactation persistency.

The genetic correlation between cumulated 270-d milk yield and F2 was moderate, indicating that selection for cumulated 270-d milk yield should raise the rate of milk yield increase to the lactation peak. Higher genetic correlations between milk yield and latent factors associated with lactation peak have been reported in dairy cattle by Macciotta et al. (2006) (0.67) and Yilmaz et al. (2011) (0.66). The genetic correlation between the latent factors ( $\mathrm{F} 1$ and F2) was low and lower than those observed by Macciotta et al. (2006) $(0 \cdot 26)$. The low correlation between the two lactation traits indicates that it may be possible, to a certain extent, to independently modify specific aspects of the lactation curve. The results of the present study are relevant since, compared with cattle, total milk yield of buffaloes is lower, the lactation length is shorter and the lactation peak is less accentuated, thus selection on the basis of total milk yield would modify components of the lactation curve as a correlated response. The present results will bring support to dairy producers to select animals in order to modify the lactation curve of dairy buffaloes through factors describing this curve.

\section{Conclusion}

Multivariate statistics employing factor analysis allowed the extraction of two variables (latent factors) that described the shape of the lactation curve. It is expected that the response to selection to increase lactation persistency is higher than the response obtained to selecting animals to increase lactation peak. Selection for higher total milk yield would result in a favourable correlated response to increase the level of production in early lactation and the lactation persistency.

\section{References}

Ali E \& Schaeffer LR 1987 Accounting for covariances among test day milk yields in dairy cows. Canadian Journal of Animal Science 67 637-644

Aspilcueta-Borquis R, Bignardi AB, Seno LO, Camargo GM, MuñozBerrocal M, Albuquerque LG, Di Palo R \& Tonhati H 2010 Genetic parameters for milk yield analyzed by test-day models in Murrah buffaloes in Brazil. Italian Journal of Animal Science 9 179-182

Chaves LC, Daher SE, Schierholt AS, Araújo CV, Dib Taxi CM, Silva CP, Brito LC, Oliveira TR, Torres RA \& Tonhati H 2010 Genetic evaluation of persistency of milk yield in dairy buffaloes using random regression model. Revista Veterinaria 21 391-391

Cobuci JA, Euclydes RF, Costa CN, Lopes PS, Torres RA \& Pereira CS 2004 Analysis of persistency in the lactation of Holstein cows using test-day yield and random regression model. Brazilian Journal of Animal Science 33 546-554

Dorneles CKP, Rorato PRN, Cobuci JA, Lopes SJ, Weber T \& Oliveira HN 2009 Lactation persisitency for Holstein cows raised in the State of Rio Grande do Sul using a random regression model. Ciência Rural 39 1485-1491

Haile-Mariam M, Bowman PL \& Goddard ME 2003 Genetic and environmental relationship among calving interval, survival, persistency of milk yield and somatic cell count in dairy cattle. Livestock Production Science 80 189-200

Jamrozik J, Schaeffer LR \& Dekkers JCM 1997 Genetic evaluation of dairy cattle using test day yields and random regression model. Journal of Dairy Science 80 1217-1226

Macciotta NPP, Vicario D \& Cappio-Borlino A 2006 Use of multivariate analysis to extract latent variables realted to level of production and lactation persistency in dairy cattle. Journal of Dairy Science $\mathbf{8 9}$ 3188-3194

Macciotta NPP, Vicario D, Dimauro C \& Cappio-Borlino A 2004 A multivariate approach to modelling shapes of individual lactation curves in cattle. Journal of Dairy Science 87 1092-1098

Misztal I 2007 BLUPF90 family of programs. http://nce.ads.uga.edu/ ignacy/ newprograms.html Accessed 12 March 2010

Muir BL, Fatehi J \& Schaeffer LR 2004 Genetic relationships between persistency and reproductive performance in first-lactation Canadian Holsteins. Journal of Dairy Science 87 3029-3037

Pool MH, Janss LLG \& Meuwissen THE 2000 Genetic parameters of Legendre polynomials for first parity lactation curves. Journal Dairy Science 83 2640-2649

Rekaya R, Carabano MJ \& Toro MA 2000 Bayesian analysis of lactation curves of Holstein-Friesian cattle. Journal of Dairy Science $\mathbf{8 3}$ 2691-2701

Rekaya R, Weigel KA \& Gianola D 2001 Hierarchical nonlinear model for persistency of milk yield in the first three lactations of Holsteins. Livestock Production Science 68 181-187

Rosati A \& Van Vleck LD 2002 Estimation of genetic parameters for milk, fat, protein and mozzarella cheese production in Italian river buffalo population. Livestock Production Science 74 185-190

Swalve HH 1995 Genetic relationship between dairy lactation persistency and yield. Journal of Animal Breeding Genetics 112 303-311

Thevamanoharan K, Vandepitte W, Mohiuddin G \& Shafique M 2000 Genetic, phenotypic and residual correlation between various performance traits of Nili-Ravi buffaloes. Buffalo Bulletin 19 80-86

Tonhati H, Muñoz MFC, Duarte JMC, Reichert RH, Oliveira JA, Lima ALF 2004 Estimates of correction factors for lactation length and genetic parameters for milk yield in buffaloes. Arquivo Brasileiro de Medicina Veterinária e Zootecnia 56 251-257 
Tonhati H, Cerón-Muñoz MF, Oliveira JO, El Faro L, Lima FAL \& Albuquerque LG 2008 Test-day milk yield as a selection criterion for dairy buffaloes (Bubalus bubalis Artiodactyla, Bovidae). Genetic Molecular Biology 31 674-679

Van der Linde R, Groen A \& de Jong G 2000 Estimation of genetic parameters for persistency of milk production in dairy cattle Proceedings of the 2000 Interbull Meeting in Bled Slovenia 14-15 May 2000 Interbull Bull 25 113-116 Available at: http://www-interbull.slu.se/bulletins/bulletin25/ van_der_Linde.pdf

Van Kaam JBCHM 1997 Gibanal: Analyzing program for Markov Chain Monte Carlo sequences version 2.4 Department of Animal Science, Wageningen Agricultural University, Wageningen, The Netherlands
Wilmink JBM 1987a Efficiency of selection for different cumulative milk, fat and protein yields in first lactation. Livestock Production Science $\mathbf{1 7}$ 211-224

Wilmink JBM 1987b Comparison of different methods of predicting 305-day milk yield using means calculated from within-herd lactation curves. Livestock Production Science 17 1-17

Yilmaz I, Eyduran E, Kaygisiz A \& Javed K 2011 Estimates of genetic parameters for lactation shape parameters with multivariate statistical technique in Brown Swiss cattle. International Journal of Agriculture Biology 13 174-178

Zicarelli L 2004 Buffalo milk: its properties, dairy yield and Mozzarella production. Veterinary Research Communication 28 127-135 